\title{
Research on the Pricing Mechanism of Photovoltaic Power Generation
}

\author{
Jianna Zhao \\ Department of Economics and Management \\ North China Electric Power University, China \\ No.689 Huadian Road, Beishi district, Baoding, 071003, \\ China \\ zhjnzhf@163.com
}

\begin{abstract}
With the vigorous development of China's green energy power market, the pricing problem of electricity market, especially the electricity market of green energy generation side, has gradually become an important issue in the reform of China's electric power structure. According to China's Development of solar photovoltaic design solar energy pricing mechanism, taking into account the importance of determining the cost of the premise, construct the theory of incentive-based solar power electricity price calculation model. The creative of this thesis is using the methods could enable the company to disclose the true cost. In order to pursue their own maximum benefit, to achieve the development and growth of enterprises, the higher cost of photovoltaic power generation companies will strive to improve production efficiency, increase $R \& D$ investment, in order to reduce the cost of photovoltaic power generation.
\end{abstract}

Keywords—solar energy; generation side; pricing mechanism; Incentive theory

\section{INTRODUCTION}

With the rapid development of world economy, energy demand will continue to grow, in the past twenty years, the world's energy consumption increased by $40 \%$, therefore, to seek new energy has become an inevitable choice to promote the sustainable development of economy and society. New energy, including wind, photovoltaic, biomass, nuclear energy, geothermal energy, ocean energy and so on, the development and utilization of human society to show a new picture. At the same time, photovoltaic as the representative of the new energy industry development has entered a new historical stage, while China has long been in the road to promote the development of photovoltaic power generation industry solid pace $^{[1]}$

However, with the vigorous development of green energy power market in China, especially the Internet price pricing problem of green energy generation side power market has gradually become an important issue related to the success of China's power structure reform. How to make the best use of photovoltaic power generation, to maximize the economic benefits, social benefits and environmental benefits, and ultimately depends on the perfect price chain, and the pricing mechanism is the key. Under the current pricing mechanism, the production cost has become the most powerful "weapon" for the government to adjust the price of supply and demand,

\author{
Wei Zhang \\ Department of Economics and Management \\ North China Electric Power University, China \\ No.689 Huadian Road, Beishi district, Baoding, 071003, \\ China \\ zhangwei7011@qq.com
}

so that the whole photovoltaic power generation industry has formed a vicious circle between cost and electricity price ${ }^{[2]}$. In order to straighten out the rights and obligations of the seller and the buyer, to cultivate a good green energy market, we must have a mature and perfect pricing mechanism as the basis, so the pricing mechanism of the study also appears to be very important.

\section{CURRENT SITUATION OF PHOTOVOLTAIC POWER GENERATION}

Photovoltaic power generation must be a perfect system to complete, the system is composed of photovoltaic battery, controller and photovoltaic grid connected inverter, photovoltaic power generation as a new energy supply mode, has been recognized by more and more countries in the world, the same is true in our country. Since 2000, under the demand of the international photovoltaic power generation market, the rapid development of photovoltaic power generation industry in China has become the world's fastest development of photovoltaic industry. According to statistics, the United Nations Environment Program, Chinese photovoltaic industry is currently more than $95 \%$ of the photovoltaic battery manufacturers and products are polycrystalline, the price is high. China's photovoltaic core power generation technology, although the development of synchronous development with the world, but the popularization and application of technology, the degree of commercialization is far behind other western developed countries ${ }^{[3]}$. Such a high cost seriously hampering the healthy development of photovoltaic industry in our country shows that the cost of photovoltaic power generation can be reduced, in order to close to or reach the conventional power production cost, become the key factor to influence the process of photovoltaic power generation.

\section{PV GENERATION SIDE ELECTRICITY PRICING MODEL}

\section{A. Pricing model assumptions based on Game Analysis of cost information}

Based on the inherent characteristics of photovoltaic power generation, in formulating the pricing model, the following assumptions should be followed to study the assumptions.

That is based on static game model, in the actual work, the power company in the government set price, the cost will be a 
false declaration information, so this article will according to the manufacturer's average level of $10 \%$ of the floating false except the financial expenses and depreciation of fixed assets of the cost calculation of actual price analysis. In this paper, the marginal cost of pricing model analysis is $90 \%$ of the cost of the report, $\theta=C^{*}(1-10 \%)$.

Assuming that the government can not accurately know the true cost of photovoltaic power generation companies, in fact, it is so, but the government can know the power generation cost of power generation costs of discrete or continuous probability distribution.

\section{B. Construction of model}

The information asymmetry between enterprises and government of photovoltaic power generation, photovoltaic power generation enterprises to master many government don't know more about the cost of information, which will enable the regulatory authorities in a short time is difficult to accurately understand PV manufacturers cost information, and in the pursuit of maximizing their own interests, photovoltaic power generation enterprises may report false cost ${ }^{[4]}$. The pricing method of power generation enterprises based on the incentive theory is to guide the real cost information of the voluntary disclosure of the photovoltaic power generation enterprises. Among them, there is no negotiation process, we put the government's pricing behavior directly set to: the government to develop photovoltaic power generation contract, photovoltaic power generation companies decided whether to accept. The photovoltaic power generation in China is just at the initial stage, the research on photovoltaic power generation pricing has not been large-scale development, this paper only considers the single principal too single agent model of power generation enterprises Yang single product.

Firstly, a cost function is set for the photovoltaic power generation enterprise.

$$
C(q)=\theta q+F
$$

Among them, $\theta$ is marginal cost of photovoltaic power generation. $\theta$ the higher the efficiency of photovoltaic power generation enterprise is lower, on the contrary, $\theta$ the lower the efficiency of photovoltaic power generation enterprise is higher; $q$ for the photovoltaic power generation enterprise power generation; $F$ for fixed costs.

The utility function of the government department is represented by $S(q)$. In economics, the marginal value of electric power products is greater than zero, and the power generation amount is monotonically decreasing, that is, with the increase of the power generation, it is strictly decreasing, so $S(q)$ is satisfied $S^{\prime}>0, S^{\prime \prime}>0, S(0)=0$.

In the case of asymmetric information, the final goal of the power generation pricing model is to achieve the government's effectiveness of the constraints and incentive compatibility constraints of photovoltaic power generation enterprises. Here too will consider the interests of the developers themselves, not to maximize the pursuit of government utility maximization of the loss of their own interests. Because the cost distribution of photovoltaic power generation enterprise is discrete and continuous, the two types are studied separately. For ease of analysis, the first set of fixed cost is zero, the marginal cost is $90 \%$ of the cost of the report, that is $\theta=C^{*}(1-10 \%)$.

According to the cost of power generation enterprises, the final power generation, photovoltaic power generation companies are assumed to be divided into two categories. $i$ represents the type of photovoltaic power generation companies, $i=1$ said the low cost type of power generation companies, $i=2$ said a high cost type of power generation companies. The probability of photovoltaic power generation enterprise is $v$, the probability of the photovoltaic power generation enterprise is the high cost type is $(1-v)$. Thus, the optimization problem becomes

$$
\max \left\{v\left[S\left(q_{1}\right)-\theta_{1} q_{1}\right]+(1-v)\left[S\left(q_{2}\right)-\theta_{2} q_{2}\right]-\left[v U_{1}+(1-v) U_{2}\right]\right\}
$$

Simplified available

$$
\begin{gathered}
\max \left\{v\left[S\left(q_{1}\right)-\theta_{1} q_{1}\right]+(1-v)\left[S\left(q_{2}\right)-\theta_{2} q_{2}\right]-v \Delta \theta q_{2}\right\} \\
\text { s.t }\left\{\begin{array}{l}
U_{1} \geq U_{2}+\Delta \theta q_{2} \\
U_{2} \geq U_{1}-\Delta \theta q_{1} \\
U_{1} \geq 0, U_{2} \geq 0
\end{array}\right.
\end{gathered}
$$

Solution available

$$
\begin{aligned}
& S^{\prime}\left(q_{1}^{S B}\right)=\theta_{1} \quad S^{\prime}\left(q_{2}^{S B}\right)=\theta_{2}+\frac{v}{1-v} \Delta \theta \quad U_{1}^{S B}=\Delta \theta q_{2}^{S B} \quad U_{2}^{S B}=0 \\
& T_{1}^{S B}=\theta_{1} q_{1}^{S B}+U_{1}^{S B} \quad T_{2}^{S B}=\theta_{2} q_{2}^{S B}
\end{aligned}
$$

Among them, $U_{1}$ and $U_{2}$ respectively for high efficiency and low efficiency of photovoltaic power generation enterprise information rent; $\theta_{i}$ generation $i$ said the marginal cost of power generation enterprises; $q_{i}$ generation $i$ power enterprises; superscript $S B$ said the optimization problem under asymmetric information; $T_{1}^{S B}$ and $T_{2}^{S B}$ respectively for the income generation of low cost and high cost of photovoltaic power generation enterprise; $\left\{T_{1}^{S B}, q_{1}^{S B}\right\}$ and $\left\{T_{2}^{S B}, q_{2}^{S B}\right\}$ for the government to provide optional power of photovoltaic power generation enterprise contract, each contract corresponding to different pricing level and photovoltaic power generation, power generation cost and is linked to each other.

Cost continuous distribution of photovoltaic power generation companies

When the photovoltaic power generation enterprise type distribution $\theta$ is continuous, the cumulative distribution function of $\theta$ is $F(\theta)$, and the cumulative distribution density is $f(\theta)$, and $f(\theta)>0, \theta \in\left[\theta_{1}, \theta_{2}\right]$. The pricing model of government departments can be expressed as 


$$
\begin{gathered}
\max \left\{\int_{\theta_{1}}^{\theta_{2}}[S(q(\theta))-\theta q-U(\theta) f(\theta)] d \theta\right\} \\
\text { s.t }\left\{\begin{array}{c}
U^{\prime}(\theta)=-q(\theta) \\
q^{\prime}(\theta) \leq 0 \\
U(\theta) \geq 0
\end{array}\right.
\end{gathered}
$$

Solution available

$$
\begin{aligned}
& S^{\prime}\left(q^{S B}(\theta)\right)=\theta+\frac{F(\theta)}{f(\theta)} \\
& U^{S B}(\theta)=\int_{\theta_{1}}^{\theta_{2}} q^{S B}(\tau) d \tau \\
& T(q)=U^{S B}\left(\theta^{S B}(q)\right)+\theta^{S B}(q) q
\end{aligned}
$$

Among them , $T(q)$ for the government to provide power generation enterprise contract. When the conditions for the establishment of the $\frac{d}{d \theta}\left(\frac{F(\theta)}{f(\theta)}\right) \geq 0$ risk rate monotonic behavior does not occur, market confusion, customers can accurately distinguish the power generation enterprise products.

The biggest advantage of the pricing model of PV power generation enterprise based on incentive theory is that it can realize the differential pricing. Among them, the efficiency of the high and low is the cost of the above mentioned different to distinguish. At the same time, the photovoltaic power generation enterprises can also show their true cost of electricity through the information rent incentives, and encourage photovoltaic power generation enterprises to real power cost, improve production efficiency, reduce the cost of power generation, to promote the rapid development of photovoltaic power generation industry.

\section{CALCULATION OF POWER GENERATION SIDE PRICING MODEL}

\section{A. Calculation of cost discrete pricing model}

Assuming the marginal cost of the two types of power generation companies $\theta_{1}, \theta_{2}$ were $0.1,0.2$, that is, the probability of the principal agent for the low cost type is 0.2 , the corresponding agent for the high cost type of probability is 0.8 . Assuming the photovoltaic power generation capacity of the ultimate utility function is $S(q)=-0.25 q^{2}+10 q$, $0 \leq q<20$, and meet the $S^{\prime}>0, S^{\prime \prime}>0, S(0)=0$.

At this point, the government determined the mathematical model of the power generation contract

$$
\begin{array}{r}
\max \left[0.2 \times\left(-0.25 q_{2}^{2}+10 q_{1}-0.1 q_{1}\right)+0.8 \times\left(-0.25 q_{1}^{2}+10 q_{2}-0.2 q_{2}\right)-\left(0.2 \times U_{1}+0.8 U_{2}\right)\right] \\
\text { s.t }\left\{\begin{array}{l}
U_{1} \geq U_{2}+0.1 q_{2} \\
U_{2} \geq U_{1}+0.1 q_{1} \\
U_{1} \geq 0, U_{2} \geq 0
\end{array}\right.
\end{array}
$$

Available

$$
S^{\prime}\left(q_{1}^{S B}\right)=19.8 \quad S^{\prime}\left(q_{2}^{S B}\right)=19.55
$$

$$
\begin{array}{ll}
U_{1}^{S B}=0 & U_{2}^{S B}=1.955 \\
T_{1}^{S B}=3.955 & T_{2}^{S B}=3.91
\end{array}
$$

The solar energy resource management department can provide the photovoltaic power generation company's alternative power generation contract respectively as follows: the electricity generation contract $\mathrm{A}\{19.8,3.935\}$, the electricity generation contract $\mathrm{B}\{19.55,3.91\}$. According to the difference of the efficiency of the photovoltaic power generation enterprise, it can be concluded that:

When the higher cost of power generation photovoltaic power generation companies, power generation revenue obtained by A selection of the contract will not be able to recover the cost of photovoltaic power generation, therefore, to maximize the benefits for the consideration of the enterprise will not choose this contract; the contract B just can compensate the cost of power generation, therefore, the power generation enterprises in high cost type will give priority to the contract $\mathrm{B}$, the choice is completely out of investment income and make a decision, it is difficult to increase the PV market share, forcing the high cost of enterprises to actively reduce their costs, in order to expand the market in profits at the same time.

When the cost of power generation photovoltaic power generation enterprises is low, due to the constraint conditions in the optimal $U_{1} \geq U_{2}+0.1 q_{2}$ situation is tight, whether to choose $\mathrm{A}$ or choose $\mathrm{B}$ contract contract results have no difference, because no matter which option contract revenue of the same, can get 1.955 of the information rent. However, if the enterprise's aim is not just a simple reproduction but also want to expand market share, namely photovoltaic power generation companies are willing to seize the market of photovoltaic power generation more power, photovoltaic power generation enterprises with low cost will eventually choose A contract. If this situation occurs, the relevant government in order to support the development of the rapid growth of solar photovoltaic power generation enterprises, most likely would slightly increase income generation of photovoltaic power generation enterprise contract, this will make the low cost of power generation produces a strong preference for the A contract ${ }^{[5]}$. Through the above analysis we can see that the government in order to ensure the smooth operation of photovoltaic power generation enterprises, photovoltaic power generation enterprise pricing will give the high cost type is 0.2 , for photovoltaic power generation enterprise pricing of low cost type is 0.198 , which can not make the high cost of enterprises are facing losses, but also increase the amount of photovoltaic power generation.

\section{B. Calculation of cost continuous pricing model}

A marginal cost of $\theta$ enterprise in $[0.1,0.2]$ interval is subject to uniform distribution, namely $f(\theta)=10$, $F(\theta)=10 \theta-1$, the likelihood ratio $\frac{d}{d \theta}\left(\frac{F(\theta)}{f(\theta)}\right) \geq 0$ can achieve the optimal conditions, the contract will not produce confusion. At this point, the photovoltaic power generation utility 
function is $S(q)=-0.25 q^{2}+10 q \quad, \quad 0 \leq q<20 \quad, \quad$ and meet $S^{\prime}>0, S^{\prime \prime}>0, S(0)=0$.

At this point, the government determined the mathematical model of the power generation contract

$$
\begin{gathered}
\max \left\{\int_{0.1}^{0.2}\left[-0.25 q(\theta)^{2}+10 q(\theta)-\theta q(\theta)-U(\theta)\right] f(\theta) d \theta\right\} \\
\text { s.t }\left\{\begin{array}{c}
U^{\prime}(\theta)=-q(\theta) \\
q^{\prime}(\theta) \leq 0 \\
U(\theta) \geq 0
\end{array}\right.
\end{gathered}
$$

Available

$$
\begin{aligned}
& q^{S B}(\theta)=20.2-4 \theta \\
& \theta^{S B}(q)=5.05-0.25 q \\
& U^{S B}(\theta)=2 \theta^{2}-20.2 \theta+3.96 \\
& T(q)=-0.125 q^{2}+5.05 q-47.045
\end{aligned}
$$

The contract form is $\left\{q,-0.125 q^{2}+5.05 q-47.045\right\}$. At this time, the type of $\theta$ photovoltaic power enterprises to obtain information on rent for $U=-0.125 q^{2}+5.05 q-47.045$. Only when $q=20.2-4 \theta$, photovoltaic power generation investors to benefit the largest, and the maximum benefit of $U=2 \theta^{2}-20.2 \theta+3.96$. Photovoltaic power generation companies with different power generation costs are able to obtain the optimal power and benefit as shown in Table 1.

Table 1 Comparison of photovoltaic power generation companies with different power generation costs

\begin{tabular}{cccc}
\hline & 0.1 & 0.15 & 0.2 \\
\hline$q^{S B}$ & 19.7 & 19.6 & 19.36 \\
$T$ & 3.94 & 3.92 & 3.88 \\
$U$ & 1.96 & 0.98 & 0 \\
$P$ & 0.198 & 0.199 & 0.2 \\
\hline
\end{tabular}

(1) The cost of power generation is the highest efficiency lowest photovoltaic power generation enterprise production minimum, the information obtained is 0 ; the minimum rent, lowest cost power generation that chooses the most efficient photovoltaic power generation enterprise's largest production, the largest rental information. From this we can know that the low cost of photovoltaic power generation enterprise production is always higher than the cost of photovoltaic power generation enterprise's output large and more revenue, which will make the enterprise continuously reduce the cost of power generation to enhance their competitiveness.

(2) In the case of asymmetric information, photovoltaic power generation enterprises generating higher cost will be lower than the optimal yield under complete information, and can get the information rent for the 0 final; the best output of photovoltaic power generation enterprise cost relatively low and will be under complete information and can obtain the same. The information rent will be greater than 0 .

(3) The low cost of photovoltaic power generation enterprises corresponding to the average price of low, high cost of photovoltaic power generation enterprises corresponding to the average price of high.

\section{SUMMARY}

Solar power generation enterprise incentive pricing method based on the theory, provides a new method for solving problems of cost information asymmetry between the government and solar power generation enterprises, not only to achieve their own economic interests, but also to promote the high cost of enterprises to actively improve the efficiency and to reduce cost, can effectively increase the competitive enterprise market share. In order to promote the development of the photovoltaic power generation. Through the above results we can analysis, as long as the assumptions can be met, no matter what is the distribution cost of photovoltaic power generation enterprises, according to the information rent incentive we build the pricing incentive model obtained is effective. In this paper, the pricing method can be used to stimulate the PV companies to present the real cost information, and increase the competition between $\mathrm{PV}$ companies $^{[6]}$. In order to pursue their own maximum income, to achieve the development and growth of enterprises, the higher cost of photovoltaic power generation companies will strive to improve production efficiency, increase $\mathrm{R} \& \mathrm{D}$ investment, in order to reduce the cost of photovoltaic power generation.

\section{ACKNOWLEDGMENT}

Under the guidance of Professor Jian-Na ZHAO through data collection and analysis of existing data, commercial banks small and micro business financial services for a more systematic analysis and research.

\section{REFERENCE}

[1] Shijingli, Research on electricity pricing mechanism and pricing policy of renewable energy[J]. China Electric Power, 2008(04):32-39.(In Chinese)

[2] Wangqinfengl, Research on electricity pricing mechanism of electricity market[D]. Fudan University,2005. (In Chinese)

[3] Le Qun Ding, Game Analysis on market power of generation companies in electricity market[J]. Electric power technology and economy, 2006(06):91-97. (In Chinese)

[4] Hua Rong Chen, China Electricity Pricing Analysis[J]. Chinese electric, 2007(01): 89-94. (In Chinese)

[5] Zhengwen, The trend of China's new energy strategy and Its Countermeasures[J]. Resource Guide, 2009(10):101-107. (In Chinese)

[6] Zhao Qiang, Analysis on the phenomenon of China's electric power industry with game theory[J]. Guangxi Electric Power, 2004(05):67-69. 